\title{
PROPOSED INDEX CALCULATION FOR ECONOMICS RANKING
}

\author{
Necati Alp Erilli ${ }^{21}$
}

Received: February 21, 2018 / Revised: May 12, 2018 / Accepted: June 20, 2018

(C) Association of Economists and Managers of the Balkans

\begin{abstract}
Index; is a display in which more than one variable is included and is used to measure the proportional variation of the movements of these variables. Indices are useful because they allow summarization and comparison by making the data simple. In this study; a new index calculation has been proposed with the help Fuzzy Clustering method. Calculation of Index prepared with 10 index values used in the literature. The indices are; Open Market, Budget Transparency, European 2020-Competitiveness, Economic Freedom (by Heritage Foundation), Economic Freedom (by Fraser Institute), Depth of credit information, Financial Stability, Trade Facilitation, Financial Inovation and Global competition. FCM Calculations are made with Matlab.2016 and other calculations are made with Microsoft Excel.2017 programmes.

There are variables which have different numbers and structures used in each index calculation. These variables have different weights within themselves. In this study, weights were calculated for the new index value which will be created by using the sequences created because of these indices. The weights of each index value obtained by the Fuzzy Clustering Analysis are multiplied by the index values to create a new index order.

European countries were re-ordered under the title "Economy". It can interpret this new index order as a general summation of all other orders. Thus, the order of the countries under different subject headings will be calculated together with the orders in a specific area (economy, law etc.).
\end{abstract}

Keywords: Index Calculation, FCM, Economics

JEL Classifications $\mathrm{C38} \cdot \mathrm{C} 43 \cdot \mathrm{C} 82$

This paper was presented at the Second International Scientific Conference on Economics and Management - EMAN 2018, March 22 2018, Ljubljana, Slovenia, www.eman-conference.org

\footnotetext{
¿ Necati Alp Erilli

aerilli@ cumhuriyet.edu.tr

21 Faculty of Economic and Administrative Sciences,, Dept. of Econometrics, Turkey
} 


\section{INTRODUCTION}

Index; is a display in which more than one variable is included and is used to measure the proportional variation of the movements of these variables. This proportional change can vary according to time or place. Therefore, indices are useful because they allow summarization and comparison by making the data simple. The indices can be used for comparisons, current situation analyzes or future estimates that are calculated for different years, settlement areas or items.

In recent years, many organizations have calculated their own index values. These indices, which do not have legal and economic sanctions, are perhaps the most important indicators in terms of showing the current situation of countries, cities or societies. It is also possible to analyze the future with different calculations of indexes made with different variables. With these indices we can see the closest position to the truth about the point and the future of mankind.

Many countries or organizations calculate their own index values in relevant areas. Indices as "Index of Mother" prepared by Save the Children Organization and "Index of Better Life" prepared by the OECD can be given as examples. These indices can be presented by sorting, by grouping or mapping observations. So that the results are both presented and visually summarized by the interested persons or institutions.

In literature, there can be seen relevant papers about indices. Carlsson and Lundström (2002) investigate what specific types of economic freedom measures are important for growth. Gwartney, Lawson and Holcombe (1999) examine the importance of economic freedom by using an index that measures economic freedom in four basic areas: Money and inflation, economic structure, takings and discriminatory taxation, and international trade. Lerman and Yitzhaki (1984) derive a convenient way to calculate the Gini coefficient, using the covariance. Harzing and Van der Wal (2009) proposed a new data source (Google Scholar) and metric (Hirsch's h $\square$ index) to assess journal impact in the field of economics and business.

\section{INDEX OF ECONOMICS}

In an economically free society, each person controls the fruits of his or her own labor and initiative. Individuals are empowered-indeed, entitled-to pursue their dreams by means of their own free choice (Miller, Kim, 2015). Economic freedom and democracy affects economic performance by identifying organizational structure. One of the important part of this performance is the index of economics. The Index of Economic Freedom is a helpful tool for a variety of audiences, including academics, policymakers, journalists, students, teachers, and those in business and finance.

Few foundations calculate his own indices with different methods. To give an example to this indices; Index of Economic Freedom (prepared by Heritage Foundation and Wall Street Journal), Economic Freedom of the World (prepared by Fraser Institute) and World Survey of Economic Freedom (prepared by Freedom House).

In an economically free society, individuals are free to work, produce, consume and invest in any way they please. With the help economic freedom index, we simply analyses the country's economic freedom levels or classify them in to similar groups. 


\section{CLUSTERING ANALYSIS}

Clustering is the assignment of a set of observations into subsets (called clusters) so that observations in the same cluster are similar in some sense. Clustering is a method of unsupervised learning, and a common technique for statistical data analysis used in many fields, including machine learning, data mining, pattern recognition, image analysis, bioinformatics and marketing.

Clustering analysis is a statistical classification technique for discovering whether the individuals of a population fall into different groups by making quantitative comparisons of multiple characteristics. The objective of cluster analysis is the classification of objects according to similarities among them and classify the data into groups (Balasko, Abonyi and Feil, 2005).

In fuzzy clustering, fuzzy techniques are used to cluster the data and with these techniques an object can be classified in more than one cluster. This approach comes into the picture as an suitable method when the clusters cannot be separated from each other distinctly or when some units are uncertain about membership.

Fuzzy clusters are functions modifying each unit between 0 and 1 which is defined as the membership of the unit in the cluster. The units which are very similar to each other hold their places in the same cluster according to their membership degree. Fuzzy clustering is based on distance measurements as well like crisp clustering algorithms. The structure of the cluster and the algorithm used to specify which of these distance criteria will be used. Some of the convenient characteristics of fuzzy clustering can be given as follows (Naes, Mevik, 1999):

i. It provides membership values which are convenient to comment on.

ii. It is flexible on the usage of distance.

iii. When some of the membership values are known, they can be combined with numeric optimization.

The advantage of fuzzy clustering over crisp clustering methods is that it provides more detailed information on the data. But there will be too much output when there are too many individuals and clusters so it will difficult to summarize and classify the data. Moreover, fuzzy clustering algorithms, which are used when there is uncertainty, are generally complicated (Oliveira, Pedrycz, 2007).

\section{FUZZY C-MEANS}

Fuzzy C-Means algorithm forms the basis of all clustering techniques that depend on objective function. It was developed by Bezdek (1974a, 1974b). When the FCM algorithm comes to a conclusion, the dots in the $\mathrm{p}$ dimension space become a sphere-shaped figure. It is assumed that these clusters are approximately the same size. Cluster centers represent each cluster and they are called prototypes. Euclidean distance $d_{i k}$ between the data and the cluster center is used as the distance measurement and can be calculated by formula given in Equation.1.

$$
d_{i k}=\left(x_{i}-v_{k}\right)=\left\|x_{i}-v_{k}\right\|=\left[\sum_{v=1}^{p}\left(x_{j i}-v_{j k}\right)^{2}\right]^{1 / 2}
$$

where $x_{k}$ represents the position observation value in the coordinated system, and $v_{i}$ represents the cluster center. It is necessary to know the actual number of clusters and the membership degrees of the individuals beforehand to be able to put this technique into practice. However, in practice, it 
is difficult to know these parameters before the application. For these, it is possible to find these values through the method of trial and error or through some techniques developed [11]. The objective function used for this clustering method is as follows:

$$
J(u, v)=\sum_{j=1}^{n} \sum_{t=1}^{c} u_{j k}^{m}\left\|x_{j i}-v_{j k}\right\|^{2}
$$

This function is the weighted least square function. $n$ parameter represents the number of observations, and $c$ represents the number of clusters. $u_{j k}^{m}$ is the membership of $x_{j}$ in $k$-th cluster, $J(u, v)$ value is a measure of the total of all weighted error sum of squares. If the $J(u, v)$ function is minimized for each value of $c$, in other words if it is derived from the 1st degree according to $v_{j}$ 's and made equal to 0 , the prototype of FCM algorithm can be given in Equation.3:

$$
v_{j k}=\frac{\sum_{j=1}^{n} u_{j k}^{m} x_{i k}}{\sum_{j=1}^{n} u_{j k}^{m}}
$$

In equation.3, it symbolizes; the number of cluster with $c$, fuzziness index with $m$, process ending criteria with $\mathcal{E}$ and membership degrees matrix with $U$ of FCM algorithm generate cluster prototypes at random. By taking means of these values, membership degrees matrix is calculated as given in Equation.4 (Sintas, Cadenas and Martin, 1999).

$$
u_{i k}=\left[\sum_{j=1}^{c}\left(\frac{d_{j i}}{d_{j k}}\right)^{\frac{2}{m-1}}\right]^{-1}
$$

$U$ cluster prototypes are updated in all iteration and the processes are repeated until $\left\|U^{(t)}-U^{(t-1)}\right\|$

value reach to previously determined error term. After FCM algorithm is implemented membership degrees are used in other to decide which individual will participate in which cluster. For each individual; the highest cluster membership is observed and this individual is added to that cluster (Erilli, Yolcu, Eğrioğlu, Aladağ and Öner, 2011).

\section{PROPOSED INDEX CALCULATION}

Indices are calculated with the help of several variables. The proposed index is calculating with fuzzy clustering analysis. The suggested steps are given as follows:

i. The variables forming each index value (they must be in the same cluster) are clustered by the fuzzy clustering analysis. (Here, it will be easier to organize the data as 2 clusters. It is the easiest method to set up a very large number of observations in addition to the observations that make up the index value for this and set the result as 2 sets).

ii. After applying the FCM method, cluster membership degrees of each observation are calculated. Cluster membership degrees take place between 0 and 1 for each observation.

iii. The membership degrees are multiplied with scores and rankings used in related indices separately.

iv. This is done for all index values which will be used in proposed index. 
At the end, two different index sequences based on both rank order and scoring are calculated.

\section{APPLICATION}

In application, it is used 10 different indices for 42 European countries to calculate new proposal index. The indices are; Open Market, Budget Transparency, European 2020-Competitiveness, Economic Freedom (by Heritage Foundation), Economic Freedom (by Fraser Institute), Depth of credit information, Financial Stability, Trade Facilitation, Financial Inovation and Global competition. FCM Calculations are made with Matlab.2016 and other calculations are made with Microsoft Excel.2017 programmes.

Every index calculation prepared with different variables. The variables used in index calculations is given below:

Economic Freedom index - Heritage Foundation (Property Rights, Freedom from corruption, Fiscal Freedom, Government Spending, Business Freedom, Labor Freedom, Monetary Freedom, Trade Freedom, Investment Freedom, Financial Freedom), European 2020 Competitiveness Index (Enterprise environment, Digital agenda, Innovative Europe, Education and training, Labour market and employment, Social inclusion, Environmental sustainability), Open Market (Trade Openness, Trade Policy Regime, Foreign Direct Investment Openness, Trade Enabling Infrastructure), Budget Transparency Index (The open budget survey results), Economic Freedom - Fraser Institute (The breadth of the State's field of activity: expenditures, taxes and initiatives, Legal structure and property rights Powerful money access International trade liberty, Legislation on credit, labor and business), Financial Stability Index (Regulatory Capital / Risk Weighted Assets, Regulatory Stage 1 Capital / Risk Weighted Assets, Unpaid Debts (Decrease in Provisions) / Capital, Unpaid Debts / Total Gross Debts), Trade Facilitation Index (market access, customs management, infrastructure and working environment), Financial Innovation Index (public expenditure, venture capital), Global competition Index (Basic requirements, infrastructure, macroeconomic situation, health and primary education)

In analysis, the variables that located in each index are clustered by FCM separately and cluster membership degrees are calculated for each observation. In Table.1, results of FCM membership degrees are given for selected countries for Open Market and Competitiveness Indices.

Table 1: FCM Results for selected indices and countries

\begin{tabular}{|c|c|c|c|c|c|c|}
\hline \multirow{2}{*}{ COUNTRIES } & \multicolumn{2}{|c|}{ Open Market } & \multirow{2}{*}{ FCM } & \multicolumn{2}{|c|}{ Competitiveness } & \multirow{2}{*}{ FCM } \\
\cline { 2 - 3 } & Ranking & Score & & Ranking & Score & \\
\hline Germany & 17 & 3,9 & 0,9966 & 7 & 5,28 & 0,9987886283 \\
\hline Albania & 34 & 3,1 & 0,9178 & 35 & 3,4 & 0,9980829292 \\
\hline Austria & 15 & 4,1 & 0,9997 & 8 & 5,16 & 0,9991957125 \\
\hline Belarus & 34 & 3,1 & 0,9178 & 35 & 3,4 & 0,9982250786 \\
\hline Belgium & 6 & 4,6 & 0,9631 & 12 & 4,93 & 0,9990932259 \\
\hline United Kingdom & 20 & 3,9 & 0,9753 & 10 & 5,13 & 0,9982526951 \\
\hline Bosnia-H. & 34 & 3,1 & 0,9178 & 35 & 3,4 & 0,9982250786 \\
\hline Bulgaria & 25 & 3,7 & 0,9987 & 31 & 3,75 & 0,9993472675 \\
\hline Czech Rep. & 11 & 4,1 & 0,992 & 21 & 4,33 & 0,9999967039 \\
\hline Denmark & 16 & 4,0 & 0,9993 & 6 & 5,32 & 0,9979980533 \\
\hline Estonia & 12 & 4,1 & 0,9967 & 15 & 4,74 & 0,9997489385 \\
\hline Finland & 21 & 3,9 & 0,9864 & 1 & 5,70 & 0,9969806536 \\
\hline
\end{tabular}




\begin{tabular}{|c|c|c|c|c|c|c|}
\hline France & 23 & 3,7 & 0,9684 & 13 & 4,81 & 0,9991981639 \\
\hline Croatia & 34 & 3,1 & 0,9178 & 27 & 3,87 & 0,9991182493 \\
\hline Netherlands & 2 & 4,8 & 0,958 & 5 & 5,41 & 0,9976840355 \\
\hline Ireland & 3 & 4,8 & 0,9579 & 14 & 4,75 & 0,9998348288 \\
\hline Spain & 26 & 3,6 & 0,952 & 16 & 4,47 & 0,9999818968 \\
\hline
\end{tabular}

The new index calculation was made separately according to the 10 index scores and rankings of the countries. The total score is calculated by multiplying the scores and the total ranking is calculated by multiplying the rankings with FCM coefficients in Microsoft Excel.

As an example, for calculation, let's get the total score of Germany. The index scores of Germanys' are given as follows: Open Market (3,9), Competitiveness $(5,28)$, Economic Freedom-Heritage $(74,2)$, Financial Stability $(34,1)$, Global competition $(5,65)$, Trade Facilitation $(5,49)$, Depth of credit information (8), Budget Transparency (69), Financial Innovation (99) and Economic Freedom-Fraser (7,68). FCM Results for same indices are; 0,9966; 0,9987; 0,9779; 0,9999; 0,9977; 0,$9998 ; 0,8219 ; 0,9565 ; 0,8587$ and 0,7056 . if we multiply the scores of each index with the results of the FCM, we get the following result: 255,9023 .

The total scores and ranking scores for all countries are calculated similarly to this example. The total order is sorted from smallest to largest and the order of the proposed index is determined according to this order. Similarly, the total scores is sorted from largest to smallest and the index order according to the scores is determined.

The index ranking obtained according to the Rankings is given in the Table 2.

Table 2: Proposed Index Ranking According to Rankings Points

\begin{tabular}{|l|l|c|l|}
\hline \multicolumn{4}{|c|}{ According to Rankings } \\
\hline 1 & Switzerland & 22 & Latvia \\
\hline 2 & Netherlands & 23 & Portugal \\
\hline 3 & United Kingdom & 24 & Slovenia \\
\hline 4 & Norway & 25 & Italy \\
\hline 5 & Finland & 26 & Romania \\
\hline 6 & Germany & 27 & Hungary \\
\hline 7 & Denmark & 28 & Turkey \\
\hline 8 & Sweden & 29 & Russia \\
\hline 9 & Luxembourg & 30 & Bulgaria \\
\hline 10 & Austria & 31 & Croatia \\
\hline 11 & Iceland & 32 & Macedonia \\
\hline 12 & Ireland & 33 & Albania \\
\hline 13 & Estonia & 34 & Cyprus \\
\hline 14 & Belgium & 36 & Ukraine \\
\hline 15 & France & 37 & Sreece \\
\hline 16 & Lithuania & 38 & Bosnia and Herzegovina \\
\hline 17 & Czech Republic & 39 & Moldova \\
\hline 18 & Poland & 40 & Montenegro \\
\hline 19 & Spain & 41 & Kosovo under UNSCR 1244/99 \\
\hline 20 & Slovakia & 42 & Belarus \\
\hline 21 & Malta & & \\
\hline & & & \\
\hline
\end{tabular}


Similarly, the index ranking obtained according to the Scores is given in the Table 3.

Table 3: Proposed Index Ranking According to Score Points

\begin{tabular}{|l|l|l|l|}
\hline \multicolumn{4}{|c|}{ According to Scores } \\
\hline 1 & Finland & 22 & Italy \\
\hline 2 & Sweden & 23 & Poland \\
\hline 3 & Denmark & 24 & Spain \\
\hline 4 & Switzerland & 25 & Slovenia \\
\hline 5 & Netherlands & 26 & Croatia \\
\hline 6 & Iceland & 27 & Romania \\
\hline 7 & Estonia & 28 & Hungary \\
\hline 8 & Norway & 29 & Bulgaria \\
\hline 9 & Austria & 30 & Cyprus \\
\hline 10 & Germany & 31 & Greece \\
\hline 11 & France & 32 & Serbia \\
\hline 12 & United Kingdom & 33 & Malta \\
\hline 13 & Belgium & 34 & Russia \\
\hline 14 & Lithuania & 35 & Macedonia \\
\hline 15 & Czech Republic & 36 & Montenegro \\
\hline 16 & Portugal & 37 & Kosovo \\
& under UNSCR 1244/99 \\
\hline 17 & Luxembourg & 38 & Moldova \\
\hline 18 & Ireland & 39 & Albania \\
\hline 19 & Latvia & 40 & Ukraine \\
\hline 20 & Turkey & 41 & Belarus \\
\hline 21 & Slovakia & Bosnia and Herzegovina \\
\hline
\end{tabular}

According to results given in Table 2 and 3, Nordic countries take place in top 10. Countries like Switzerland, United Kingdom and Netherlands are other countries at the top.

The question of which index order is more important here may come to mind. It may be thought that the sequential calculation is more realistic. Because there is a difference between the scorers, but the ranking is always between 1 and 42. Thus, the calculation shows that it performs with a certain range and minimum variance. The correlation coefficient between the two calculations is found as 0,922 and it is significant at level 0,01.

Finally, if we perform FCM to all countries with all scores we get 6 clusters according to economics variables. Classification results is given in Table 4:

Table 4: FCM Results for European Countries

\begin{tabular}{|c|c|c|c|c|c|}
\hline Cluster I & Cluster II & Cluster III & Cluster IV & Cluster V & Cluster VI \\
\hline Netherlands & Germany & Belgium & $\begin{array}{c}\text { Czech } \\
\text { Republic }\end{array}$ & Bulgaria & Albania \\
\hline Switzerland & Austria & Ireland & Estonia & Italy & Belarus \\
\hline Luxembourg & $\begin{array}{c}\text { United } \\
\text { Kingdom }\end{array}$ & Malta & France & Cyprus & $\begin{array}{c}\text { Bosnia and } \\
\text { Herzegovina }\end{array}$ \\
\hline & Denmark & & Spain & Hungary & Croatia \\
\hline & Finland & & Latvia & Poland & Montenegro \\
\hline
\end{tabular}




\begin{tabular}{|c|c|c|c|c|c|}
\hline & Sweden & & Lithuania & Romania & $\begin{array}{c}\text { Kosovo under } \\
\text { UNSCR 1244/99 }\end{array}$ \\
\hline & Iceland & & Portugal & Turkey & Macedonia \\
\hline & Norway & & Slovakia & & Moldova \\
\hline & & & Slovenia & & Russia \\
\hline & & & & & Serbia \\
\hline & & & & & Ukraine \\
\hline & & & & & Greece \\
\hline
\end{tabular}

Looking to Table 4, we can say that first 2 cluster can be named as "Strong Economies", cluster 3 and 4 can be named as "Medium-Level Economies", cluster 5 and 6 can be named as "Weak Economies" for the European countries.

\section{CONCLUSION}

Today, many different indices are being calculated. The aim here is to see the current situation of the relevant countries, cities or companies and to compare them with the other competitors. All indices are using different types of variables and methods. So that different index results can be seen in the same area.

In this study, it is used Fuzzy Clustering Analysis to determine Index of Economics. A new index calculation has been proposed with the aid of 10 different index calculations previously calculated for the economics. The fuzzy clustering analysis was used in the proposed calculation. The proposed method is based on the scores and rankings aids used in previous index calculations.

According to the results of the analysis, the Nordic countries, Switzerland, Netherlands and the United Kingdom were in the top rankings in both index lists. It should not be surprising that these countries, which have strong economies, are also ranked high in their high prosperity rankings.

With different methods, organizations can better analyze their current situation. With the help of this study, it has been presented that fuzzy classification methods can be successfully used for index calculation or ranking measures.

\section{REFERENCES}

Balasko, B., Abonyi J., Feil B., (2005). Fuzzy Clustering and Data Analysis Toolbox. Univ. Of Veszprem, Hungary.

Bezdek, J. C. (1974a). Cluster validity with fuzzy sets. J. Cybernetics 3, 58-73

Bezdek, J. C. (1974b). Numerical Taxonomy with Fuzzy Sets. J. Math Biol. 1, 57-71

Carlsson, F., Lundström, S. (2002). Economic Freedom and Growth: Decomposing the Effects. Public Choice, 112, 335-344.

Erilli, N. A., Yolcu, U., Eğrioğlu, E., Aladağ, Ç.H., Öner, Y. (2011). Determining the Most Proper Number of Cluster in Fuzzy Clustering by Artificial Neural Networks. Expert Systems with Applications, 38, 2248-2252.

Gwartney, J. G., Lawson, R. A., Holcombe, R. G. (1999). Economic Freedom and the Environment for Economic Growth. Journal of Institutional and Theoretical Economics, 155(4), 643-663.

Harzing, A. W., Van der Wal, R. (2009). A Google Scholar h $\square$ index for journals: An alternative metric to measure journal impact in economics and business. Journal of Asso. for Information Science and Technology, 60(1), 41-46.

Lerman, R. I., Yitzhaki, S. (1984). A note on the calculation and interpretation of the Gini index. Economics Letters, 15(3-4), 363-368. 
Miller, T. Kim, A. B., (2015). Chapter 1: Principles of Economic Freedom, http://www.heritage.org/index/pdf/2015/book/chapter1.pdf

Naes T., Mevik T. H., (1999). The Flexibility of Fuzzy Clustering Illustred By Examples, Journal Of Chemo Metrics.

Oliveira, J. V., Pedrycz, W. (2007). Advances In Fuzzy Clustering And Its Applications, John Wiley $\&$ Sons Inc. Pub., West Sussex, England.

Sintas, A. F., Cadenas, J.M., Martin, F. (1999). Membership functions in the Fuzzy c-Means Algorithm, Fuzzy Sets and Systems. 